\title{
HEALING POTENCY OF HAEMATOCOCCUS PLUVIALIS EXTRACT FOR TREATING TYPE 2 DIABETES IN RATS
}

\author{
FAROUK K. EL-BAZ ${ }^{1}$, HANAN F. ALY ${ }^{2}$, SAYEDA M. ABDO ${ }^{3}$, SAFAA A. SAAD ${ }^{1}$
}

1Plant Biochemistry Department, ${ }^{2}$ Therapeutic Chemistry, Department, ${ }^{3}$ Water pollution Research Department, National Research Centre (NRC), 33 El Bohouth st. (former El Tahrir st.), Dokki, Giza, Egypt, P. 0.12622

Email: fa elbaz@hotmail.com

Received: 11 Oct 2016 Revised and Accepted: 18 Nov 2016

\begin{abstract}
Objective: The present study aims to evaluate the antidiabetic effect of ethanolic extract of Haematococcus pluvialis (H. pluvialis) in streptozotocin (STZ)-induced diabetic rats.

Methods: The antidiabetic activity of $H$. pluvialis was investigated by the determination of glucose and insulin levels, aspartate (AST), alanine transaminases (ALT), lipid profile including total cholesterol (TC), triglycerides (TG), low-density lipoprotein-cholesterol (LDL-C) and high-densitylipoprotein-cholesterol (HDL-C). Histopathological examination of pancreas and liver were also carried out.

Results: The results revealed that the levels of glucose, TC, TG, LDL-C as well as AST and ALT enzyme activities were increased significantly in diabetic rats. While, insulin and HDL-C levels decreased significantly in STZ-induced diabetic rats. The remediation of diabetic rats with $H$. pluvialis attenuated the elevated levels of glucose, TC, TG, LDL-C as well as AST and ALT activities in diabetic rats. Besides, it improved insulin, HDL-C levels, pancreas and hepatic architectures.
\end{abstract}

Conclusion: H. pluvialis extract has a promising antidiabetic potency through attenuation of several metabolic disorders associated diabetes.

Keywords: Diabetes mellitus, Haematococcus pluvialis, STZ, Liver enzymes, Lipid profile

(C) 2017 The Authors. Published by Innovare Academic Sciences Pvt Ltd. This is an open access article under the CC BY license (http://creativecommons.org/licenses/by/4. 0/) DOI: http://dx.doi.org/10.22159/ijpps.2017v9i1.15629.

\section{INTRODUCTION}

Diabetes mellitus (DM) is a complex disorder that is categorised into two large types; insulin-dependent diabetes mellitus (type 1 diabetes) and non-insulin-dependent diabetes mellitus (type 2 diabetes) [1]. Type 2 diabetes mellitus (T2DM) represents the main state of diabetes around the world that is attributed to different causes such as, unhealthy habits; sedentary lifestyle and obesity [2]. T2DM therapies including, insulin, sulfonylureas, thiazolidinedione's, metformin and $\alpha$-glucosidase inhibitors may have limited efficacy or significant mechanism that lead to side effects like hypoglycemia, flatulence, body weight gain and enhancement of gastrointestinal problems [1]. Hence, searching for new natural antidiabetic therapies for combating diabetes has become an urgent matter.

Different types of algae, specifically microalgae, contain important vitamins such as: vitamins $A_{1}, B_{1}, B_{2}, B_{3}, B_{6}, B_{9}, B_{12}, C, D, E$ and $H$ which are considered as potent and valuable sources of bioactive compounds and may be applied in pharmaceutical, nutraceutical and cosmetic sectors [3]. H. pluvialis is a unicellular green microalga that enters in many industries; nutraceuticals, pharmaceuticals, cosmetics, aquaculture and nutritious [4]. This freshwater alga belongs to the family of Haematococcaceae which contains compounds including fatty acids (lauric, myristic, palmitic, palmitoleic, margaric, oleic, lignoceric, gadoleic), vitamins $\left(\mathrm{B}_{1}, \mathrm{~B}_{2}\right.$, $\mathrm{B}_{3}, \mathrm{~B}_{5}, \mathrm{~B}_{9}, \mathrm{~B}_{6}, \mathrm{~B}_{12}, \mathrm{C}$ and $\mathrm{E}$ ) and carotenoids (astaxanthin (ASTA), canthaxanthin, echinenone, lutein and $\beta$-carotene).

ASTA is a natural red carotenoid pigment which occurs in different sources such as microalgae, trout, salmon and shrimp [5]. $H$. pluvialis, Chlorella zofigiensis and Chlorococcum sp. are the main sources of ASTA however; the amounts of ASTA (up to 4-5\% of dry weight) in $H$. pluvials are higher than any other source [6]. Throughout the last few years, there is a rapidly developed research on the health benefits of ASTA due to it is considered as a powerful agent in the protection of oxidative stress-related diseases [5]. Depending on looking for green solutions, the natural ASTA pigment from $H$. pluvialis seems to be better than its synthetic counterpart because of structure, function, application and safety [7]. It was reported that ASTA has a potential effect against different chronic inflammatory disorders, including cancer, asthma, rheumatoid arthritis, metabolic syndrome, gastrointestinal, hepatic and neurodegenerative diseases [8].

Therefore, the aim of the current work is to investigate the efficiency role of $H$. pluvialis ethanolic extract to attenuate metabolic disorder associated diabetes in STZ-induced rats.

\section{MATERIALS AND METHODS}

Chemical, reagents and standards

STZ was purchased from Sigma-Aldrich, India. All chemicals in the present study were of analytical grade, products of Sigma, Merck and Aldrich. All kits were the products of Biosystems (Alcobendas, Madrid, Spain), Sigma Chemical Company (St. Louis, MO, USA), Biodiagnostic Company (Cairo, Egypt).

\section{H. pluvialis cultivation}

H. pluvialis (strain No. CCAP 34/7) was isolated by spreading $0.1 \mathrm{ml}$ of water samples collected from Nile River phytoplankton using BG11 media for algal isolation [9] into Petri dishes containing 1.5\% agar for solidification. Then, single colonies of algae were recultivated in the specified liquid media as non-axenic batch cultures (50 ml) at $25 \pm 2{ }^{\circ} \mathrm{C}$ and $24 \mathrm{~h}$ with continuous white fluorescent lamp intensity $\approx 2500$ Lux. Cultivation was carried out on an open pond with a capacity of $70 \mathrm{l}$ containing $55 \mathrm{l}$ of growth media. After cultivation, the biomass was initially separated from the water by gravitational settling and then further concentrated by centrifugation [10], then dried at $40{ }^{\circ} \mathrm{C}$.

\section{Preparation of ethanolic extract}

$100 \mathrm{~g}$ of the powder algae were macerated in ethanol (80\%) and shacked on a shaker (Heidolph UNIMAX 2010) for $48 \mathrm{~h}$ at 150 rpm. The extract was filtered using a Buchner funnel and 
Whatman No. 4 filter paper and the algal residue was reextracted with the addition of fresh ethanol for another two times [11]. Combined filtrates were concentrated using Rotavapor (Heidolph-Germany) at a temperature of $40{ }^{\circ} \mathrm{C}$ under vacuum to dryness. The evaporated extract so obtained was preserved at $-20^{\circ} \mathrm{C}$ in a freeze and kept until further use.

\section{Animals}

Fifty male Wistar rats (180-200 g) raised in the Central Animal House, National Research Centre (NRC) were used. Animals were acclimatised to the laboratory conditions at room temperature prior to the experimentation. Animals were kept under standard conditions of a $12 \mathrm{~h}$ light/dark cycle with food and water in plastic cages with soft bedding. Before testing for blood glucose level or injection of streptozotocin to induce diabetes, the rats were fasted overnight (at least $12 \mathrm{~h}$ ) but had free access to water. The study was approved by the NRC animal Ethical Committee Guidelines (approval no: 0112459) for the use and care of animals.

\section{Diabetes induction and animals' treatment}

STZ was dissolved in $0.01 \mathrm{M}$ citrate buffer immediately before use and induced by intraperitoneally injection of a single dose ( $45 \mathrm{mg} / \mathrm{kg} \mathrm{b}$. wt.) through the dorsal vein of the rats' penis [12]. After STZ injection, rats had free access to food, water and were given $5 \%$ glucose solution to drink overnight to encounter hypoglycemic shock [13].

Fasted blood glucose levels were assessed $72 \mathrm{~h}$ after STZ injection as well as glycosuria to confirm the diabetic states. Rats were considered to be diabetic if glycosuria was present for 3 consecutive days [14]. Only rats with a fasting blood glucose level of $\geq 300 \mathrm{mg} / \mathrm{dl}$ and positive urine glucose were used in the experiment. The antidiuretic glibenclamide reference drug was orally administrated at a dose $10 \mathrm{mg} / \mathrm{kg}$ b. wt. daily for $30 \mathrm{~d}$ [15].

\section{Experimental study}

Fifty rats were randomly divided into 5 groups of ten in each group. Group 1: Normal control. Group 2: Normal rats treated with $H$. pluvialis ethanolic extract (150 mg/Kg b. wt.) [16], group 3: Diabetic rats. Groups 4: Diabetic rats orally administered with $H$. pluvialis ethanolic extract (150 mg/Kg b. wt.). Group 5: Diabetic rats orally administered antidiabetic glibenclamide reference drug $(10 \mathrm{mg} / \mathrm{kg}$ b. wt.) daily for $30 \mathrm{~d}$.

\section{Blood sampling, tissue samples and serum measurements}

Rats fasted overnight (12-14 h), anaesthetized by diethyl ether and blood collected by puncture of the sublingual vein in clean and dry test tube, left $10 \mathrm{~min}$ to clot and centrifuged at $3000 \mathrm{rpm}$ for serum. The separated serum was used for biochemical analysis of glucose, insulin, TC, TG, HDL-C and LDL-C levels, AST and ALT activities

\section{Biochemical analysis}

\section{Glucose level}

Serum glucose level was determined calorimetrically according to the method described by Trinder [17].

\section{Insulin activity}

Insulin was determined by Insulin quantitative test kit according to the method of Sacks [18] based on a solid phase enzyme-linked immunosorbent assay.

\section{Liver enzymes activity}

Serum AST and ALT activities were determined according to the method of Reitman and Frankel [19].

\section{Lipid profile (TC, TG, LDL-C and HDL-C) levels}

Serum TC level was determined using diagnostic kit according to the method of Allain et al. [20]. TG level was determined by the method of Fassati and Prencipe [21]. LDL-C was determined by the method of Assmann et al. [22]. HDL-C was determined by the method of Stein [23].

\section{Histopathological examinations}

At the end of the experiment, rats were sacrificed and the pancreas and liver samples were dissected and extracted from animals. Pancreas and liver tissues were fixed in $10 \%$ formalin for one week, washed in running tap water for $24 \mathrm{~h}$ and dehydrated in ascending series of ethanol (50-90\%), followed by absolute alcohol. The samples were cleared in xylene and immersed in a mixture of xylene and paraffin at $60^{\circ} \mathrm{C}$. The tissue was then transferred to pure paraffin wax of the melting point $58^{\circ} \mathrm{C}$ and then mounted in blocks and left at $4{ }^{\circ} \mathrm{C}$. Serial sections of 5 microns thick were prepared and mounted on clean glass slides and left in the oven at $40{ }^{\circ} \mathrm{C}$ to dryness. The slides were deparaffinized in xylene and then immersed in descending series of ethanol (90-50\%). The ordinary haematoxylin and eosin (H and E) stain was used to stain the slides [24].

\section{Statistical analysis}

All the values of fasting blood sugar, biochemical estimations were expressed as mean \pm SD (Standard Deviation). Statistical differences between the means of the various groups were evaluated by oneway analysis of variance (ANOVA) using the Statistical Package for the Social Sciences (SPSS) program, version 11 followed by Co-state statistical program to compare significance between groups, where unshared letters are considered significant at $\mathrm{P} \leq 0.05$.

\section{RESULTS AND DISCUSSION}

\section{Influence of $H$. pluvialis extract on glucose and insulin levels}

Glucose and insulin levels in different therapeutic groups are demonstrated in the table (1). Insignificant difference in blood glucose and insulin levels was recorded between untreated normal control and treated one with $H$. pluvialis extract. While a significant increase in glucose level was recorded in diabetic rats with percentage $218.35 \%$, compared to normal control rats.

However, insulin revealed a significant decrease in its level with percentage $54.25 \%$. Treatment of diabetic rats with $H$. pluvialis extract showed a reduction in glucose level with amelioration percent $177.15 \%$. While insulin level recorded significantly increased with the percentage of amelioration $62.21 \%$. Also, glibenclamide standard drug showed improvement in blood glucose and insulin levels with amelioration percent 167.69 and $8.23 \%$, respectively.

Table 1: Changes in blood glucose and insulin levels in different experimental groups

\begin{tabular}{|c|c|c|c|c|c|}
\hline Groups parameters & Control & Control+H. pluvialis & Diabetes & Diabetes+H. pluvialis & Diabetes+drug \\
\hline Glucose (mg/dl) & $106.8 \pm 3.9^{a}$ & $90.15 \pm 3.18^{b}$ & $340.00 \pm 18.00^{c}$ & $150.80 \pm 10.80^{\mathrm{d}}$ & $160.90 \pm 9.85^{\mathrm{d}}$ \\
\hline$\%$ Change & - & 15.58 & 218.35 & 41.19 & 50.65 \\
\hline$\%$ of improvement & - & - & - & 177.15 & 167.69 \\
\hline Insulin $(\mu \mathrm{IU} / \mathrm{ml})$ & $7.41 \pm 0.8^{\text {a }}$ & $8.00 \pm 0.5^{b}$ & $3.39 \pm 0.02^{\mathrm{c}}$ & $8.00 \pm 2.6^{\mathrm{a}}$ & $4.00 \pm 2.11^{\mathrm{c}}$ \\
\hline$\%$ Change & - & 7.96 & 54.25 & 7.96 & 46.01 \\
\hline$\%$ of improvement & - & - & - & 62.21 & 8.23 \\
\hline
\end{tabular}

1-Data are expressed as mean \pm SD of ten rats in each group. 2-Statistical analysis is carried out using SPSS computer program (one way ANOVA) coupled with Co-state computer program, where unshared letters are significant at $\mathrm{P} \leq 0.05$. 


\section{CALCULATION}

$$
\begin{gathered}
\% \text { Change to control }=\frac{\text { Mean of control }- \text { mean of treated }}{\text { Mean of control }} \times 100 \\
\% \text { of improvement }=\frac{\text { Mean of disease }- \text { mean of treated }}{\text { Mean of control }} \times 100
\end{gathered}
$$

DM, a group of metabolic disorders of the endocrine system characterised by hyperglycaemia, contributes to death in several developed and developing countries [25]. According to the present results, the glucose level of diabetic rats revealed an increase in blood glucose level (218.35\%), comparing to normal control rats. This finding is in agreement with those obtained by Nizamutdinova et al. [26] and El-Baz et al. [27] who found that glucose level increased in rats after STZ induction which may be attributed to, the irreversible destruction of the pancreatic $\beta$-islet cells and consequently reducing insulin secretion.

However, the supplementation of diabetic rats with $H$. pluvialis ethanolic extract exhibited a decrease in the blood glucose level with improvement percentage reached to $177.15 \%$ as compared to normal control rats. In a parallel results Uchiyama et al. [28], declared, reduction in blood glucose level in mice after treatment with Astaxanthin (ASTA). The same authors suggested that the anti-oxidants may be potentially useful for reducing glucose toxicity.

Further, oxidative stress encouraged by hyperglycemia insult may result in pancreatic $\beta$-cells dysfunction in DM state. ASTA, a carotenoid of marine microalgae, is considered as a powerful antioxidant that can inhibit lipid peroxidation and scavenge reactive oxygen species (ROS) [28]. Moreover, ROS production, activation of transcription factors, cytokine expression and production by normal human mesangial cells enhanced by hyperglycemia were significantly suppressed by ASTA treatment [29].

The deficiency in insulin secretion or action site is considered the main causes responsible for DM [25]. In the present study, diabetic rats exhibited a significant decrease in insulin level (54.25\%), comparing to normal control rats. These results are run in parallel with the results of Gandhi and Sasikumar [30] who observed a significant decrease in insulin level post induction with STZ. This reduction may be related to, the induction of STZ enhance degenerative changes in $\beta$-cells leading to decreases in the number of functioning $\beta$-cells [31]. Thus, T2DM is accompanied with insufficient secretion of insulin from the pancreatic $\beta$-cells and impaired insulin action in target tissues including liver, muscle and fat [32].

Meanwhile, diabetic rats treated with $H$. pluvialis showed enhancement in insulin level with percentage $62.21 \%$. This result is agreed with the study of Preuss et al. [33] who declared that ASTA beneficially improved both sucrose-induced elevation of blood pressure and insulin resistance in rats. Due to oxidative stress encourages insulin resistance in T2DM, it is critical to find effective antioxidant to upgrade this damage [5].

So, the improved insulin level upon using $H$. pluvialis extract may rely on the hypothesis of Regnier et al. [34] who found the antioxidant activity of ASTA may contribute to a decrease the risk of oxidative stress-related diseases. Where, the antioxidant activity of ASTA is 65 times more potential than vitamin C, 54 times higher than $\beta$-carotene and 100 times more active than $\alpha$ tocopherol [7].

\section{Influence of $\boldsymbol{H}$. pluvialis extract on liver enzymes activity}

Table (2) demonstrated the AST and ALT enzyme activities in different experimental groups. An insignificant difference was recorded in liver enzyme activities in treated rats with $H$. pluvialis extract as compared to untreated normal control one. Diabetic rats declared significant elevation in AST and ALT activities with percentages 94.40 and $50.57 \%$, respectively as compared to control group. However, H. pluvialis treatment attenuated the elevation in AST and ALT activities with improvement percentages 90.04 and $35.19 \%$, respectively. While the amelioration percent in AST and ALT activities reached to 87.45 and $39.03 \%$, respectively upon using glibenclamide antidiabetic drug.

\begin{tabular}{|c|c|c|c|c|c|}
\hline Groups parameters & Control & Control+H. pluvialis & Diabetes & Diabetes+H. pluvialis & Diabetes+drug \\
\hline AST (U/l) & $22.71 \pm 1.28^{a}$ & $23.12 \pm 2.10^{\mathrm{a}}$ & $44.15 \pm 2.19^{b}$ & $23.70 \pm 2.15^{\mathrm{a}}$ & $24.29 \pm 1.90^{\mathrm{a}}$ \\
\hline$\%$ Change & - & 1.80 & 94.40 & 4.35 & 6.95 \\
\hline$\%$ of improvement & - & - & - & 90.04 & 87.45 \\
\hline $\operatorname{ALT}(U / \mathrm{l})$ & $26.00 \pm 2.12^{\mathrm{a}}$ & $27.00 \pm 2.34^{\mathrm{a}}$ & $39.15 \pm 2.10^{b}$ & $30.00 \pm 2.7 \mathrm{a}$ & $29.00 \pm 2.12^{\mathrm{a}}$ \\
\hline$\%$ Change & - & 3.84 & 50.57 & 15.38 & 11.53 \\
\hline$\%$ of improvement & - & - & - & 35.19 & 39.03 \\
\hline
\end{tabular}

Table 2: Changes in liver enzyme activities; AST and ALT in different experimental groups

1-Data are expressed as mean \pm SD of ten rats in each group. 2-Statistical analysis is carried out using SPSS computer program (one way ANOVA) coupled with Co-state computer program, where unshared letters are significant at $\mathrm{P} \leq 0.05$.

\section{AST and ALT (aspartate and alanine aminotransferases)}

Regarding the current findings, AST and ALT activities were significantly increased in the diabetic status with percentages 94.40 and $50.57 \%$, respectively as compared to the normal control rats. The recent results are in accordance with the results of Sireesha and Sailaja [35] and El-Baz et al. [27], who displayed a significant increase in both AST and ALT activities in diabetic condition and related these increments to the destruction of hepatic cells and the enzymes leakage into the circulation are likely the responsible for alterations in enzyme activities levels. H. pluvialis extract improved the activities of AST and ALT by percentages 90.04 and 35.19\%, respectively.

Hamdena et al. [36] explained that STZ encourages hyperglycemia resulting in the over-production of free radicals, the inactivation of antioxidant enzymes by the non-enzymatic glycation of proteins and subsequently causes harmful effects on $\beta$-cells function. On the other hand, both of ASTA and oleic acid enhance maximum antioxidant capacity and seem most adequate for human consumption in nutraceuticals or pharmaceuticals [37]. So, ASAT and oleic acid of H. pluvialis extract may be responsible for the ameliorative effect in AST and ALT activities in diabetic condition.

\section{Influence of $\boldsymbol{H}$. pluvialis extract on lipid profile}

Table (3) clearly indicated an insignificant change in lipid profile levels in normal rats treated with H. pluvialis extract as compared to untreated control rats. However, diabetic rats recorded significant elevation in TC, TG and LDL-C levels with percentages 74.54, 57.46 and $140.88 \%$, respectively.

While HDL-C level exhibited significantly decreased (39.88\%) as compared to control rats. Treatment of diabetic rats with $H$. pluvialis extract showed amelioration in TC, TG, LDL-C and HDL-C levels by percentages 61.93, 57.66, 129.33 and $35.81 \%$, respectively. While, the percentages of amelioration recorded $3.41,51.66,82.66$ and $19.81 \%$, respectively upon using glibenclamide antidiabetic drug. 
Table 3: Changes in lipid profile levels in different experimental groups

\begin{tabular}{|c|c|c|c|c|c|}
\hline Groups parameters & Control & Control+H. pluvialis & Diabetes & Diabetes $+H$. pluvialis & Diabetes+drug \\
\hline $\mathrm{TC}(\mathrm{mg} / \mathrm{dl})$ & $88.80 \pm 4.34^{a}$ & $75.90 \pm 3.43^{a}$ & $155.00 \pm 9.0^{b}$ & $100.00 \pm 7.6^{c}$ & $120.00 \pm 2.10^{\mathrm{d}}$ \\
\hline$\%$ Change & - & 41.52 & 74.54 & 12.61 & 35.13 \\
\hline$\%$ of improvement & - & - & - & 61.93 & 39.41 \\
\hline $\mathrm{TG}(\mathrm{mg} / \mathrm{dl})$ & $56.71 \pm 1.4^{a}$ & $45.40 \pm 3.16^{\mathrm{c}}$ & $89.30 \pm 4.14^{b}$ & $56.60 \pm 2.3^{a}$ & $60.00 \pm 3.15^{\mathrm{a}}$ \\
\hline$\%$ Change & - & 19.94 & 57.46 & 0.19 & 5.80 \\
\hline$\%$ of improvement & - & - & - & 57.66 & 51.66 \\
\hline LDL-C (mg/dl) & $37.50 \pm 2.95^{a}$ & $25.52 \pm 1.62^{\mathrm{b}}$ & $90.33 \pm 6.97 \mathrm{c}$ & $41.83 \pm 2.18^{\mathrm{a}}$ & $59.00 \pm 1.77 \mathrm{c}$ \\
\hline$\%$ Change & - & 31.94 & 140.88 & 11.54 & 57.33 \\
\hline$\%$ of improvement & - & - & - & 129.33 & 82.66 \\
\hline HDL-C (mg/dl) & $50.17 \pm 2.15^{a}$ & $55.71 \pm 3.18^{a}$ & $30.16 \pm 3.15^{b}$ & $48.13 \pm 2.92^{\mathrm{a}}$ & $40.10 \pm 4.32^{c}$ \\
\hline$\%$ Change & - & 11.04 & 39.88 & 4.06 & 20.07 \\
\hline$\%$ of improvement & - & - & - & 35.81 & 19.81 \\
\hline
\end{tabular}

1-Data are expressed as mean $\pm S D$ often rats in each experiment, 2-Statistical analysis is carried out using SPSS computer program (one way ANOVA) coupled with Co-state computer program, where unshared letters are significant at P $\leq 0.05$, 3-TC (Total cholesterol, TG (triglycerides), LDLC low-density lipoprotein-cholesterol), HDL-C (high-density lipoprotein cholesterol).

Impaired lipid profile is a strong risk agent in T2DM where, coronary atherosclerosis is positively related with proatherogenic lipids (TC, LDL-C and TG) and negatively correlated with HDL-C [38]. With respect to lipid profile in diabetic rats, the levels of TC, TG and LDL-C were significantly elevated with percentages; $74.54,57.46$ and $140.88 \%$, respectively as compared to normal control rats. While, HDL-C level was decreased $(39.88 \%)$. The increased level of TC in the diabetic state may be explained on the hypothesis that, hyperphagia of diabetes enhances the increased activity of HMGCoA reductase of the intestine leading to increasing cholesterol synthesis in plasma [39]. The same authors also added that hypertriglyceridemia may related to higher rates of TG production rich very-low-density lipoprotein (VLDL) by the liver in addition to, the decreased removal of $\mathrm{TG}$ by peripheral tissues-primarily adipose tissue and muscle.

InT2DM, when triglyceride-rich lipoproteins are high, the exchange of cholesteryl esters in HDL particles for TG in triglyceride-rich lipoproteins is increased, an exchange mediated by cholesteryl ester transfer protein (CETP) leading to reduce the levels of HDL-C in plasma [40]. Also, the reduced HDL-C levels in diabetic condition is a result of insufficiency in fatty acid metabolism, increased gluconeogenesis and high production of ketone bodies that consequently may rise to hypercholesterolemia and hypertriglyceridemia which represent the most commonly obtained lipid abnormalities in DM [41]. The increase in LDLs is likely connected with hypertriglyceridemia where the increased level of triglyceriderich lipoprotein in T2DM stimulates CETP activity and the transfer of triglycerides to LDLs causing to the formation of small dense triglyceride-rich LDL particles [42].

Considering diabetic rats treated with $H$. pluvialis extract, the levels of TC, TG, LDL-C and HDL-C were improved by percentages 61.93 , 5766, 129.33 and $35.81 \%$, respectively. It was found that ASTA possesses several biological effects including antioxidant, anticancer, anti-inflammatory besides; it improves dyslipidemia [43, 44]. Moreover, ASTA has the ability to preserve the membrane consistency, inhibit the formation of lipid peroxide, reduces the accumulation of lipid in lipid-loaded hepatocytes via acting as a peroxisome proliferator-activated receptor $\alpha$ (PPAR- $\alpha$ ) agonist and PPAR- $\gamma$ antagonist $[45,46]$. An in vivo study showed that ASTA depletes the increased peroxisome proliferator activated receptor$\gamma$ coactivator $1-\alpha(\mathrm{PGC}-1 \alpha)$ in skeletal muscle, resulting in the speed usage of lipid, as an outcome of initialization of mitochondrial aerobic metabolism [47]. Therefore, the ameliorations in lipid profile levels in diabetic rats post treatment with $H$. pluvialis extract may be related to ASTA found in $H$. pluvialis microalgae. Moreover, the hypocholesterolemic effect of ASTA may be contribute to increase in the hepatic expression of LDL receptor that facilitates LDL uptake to the liver . Beside ,the ASTA triglyceride-lowering effect may be related to increase in the expression of the gene involved in fatty acid $\beta$-oxidation [48].

\section{Pancreas histology}

Microscopically, the pancreas of normal control rats revealed normal histologicals structure of pancreatic acini and islets of Langerhan's (photomicrograph 1). Meanwhile, sections from diabetic rats showed vacuolations and congestion of islets of Langerhans as well as focal necrosis of pancreatic acini associated with inflammatory cells infiltration (photomicrographs $2 \mathrm{a}$ and $2 \mathrm{~b}$ ). Examined sections from diabetic rats treated with $H$. pluvialis extract revealed slight vacuolation of cells of islets of Langerhans (photomicrograph 3). Also, the pancreas of rat from diabetic rats treated with glibenclamide drug revealed slight vacuolation of cells of islet's of Langerhan's (photomicrograph 4).

Histopathological examination of diabetic rats in the present results are agreed with the results of Sheweita et al. [49] who observed that, the induction of STZ at a dose $45 \mathrm{mg} / \mathrm{kg}$ led to disturbance of the acini pattern structure, pyknotic nuclei of some acini cells with severe damage, dilation, congestion and thickening of blood vessels, vacuolated acini, vacuolated cytoplasm and degeneration of $\beta$-islet cells.

However, the pancreatic architecture of rats treated with $H$. pluvialis extract displayed slight vacuolation of islet's Langerhan's cells compared to glibenclamide -treated diabetic rats. (Photomicrograph's 3, 4). This improvement could be due to; H. pluvialis contain high amounts of ASTA that can preserve $\beta$-cell function leading to exert beneficial effects in the diabetic state [28].

Additionally, Hussein et al. [50] also suggested that ASTA improved both of insulin sensitivity and resistance as it protected the pancreatic $\beta$-cells from glucose toxicity via preventing the progression of $\beta$-cells destruction in diabetic mice.

\section{Liver histology}

Microscopically, liver of normal control rats revealed the normal histological structure of hepatic lobules (photomicrograph 5). Meanwhile, liver of diabetic rats showed Kupffer cells activation, cytoplasmic vacuolization of hepatocytes, cystic dilatation of bile duct and fibroblasts proliferation in the portal triad around the bile duct (photomicrographs 6a and 6b).

The improved picture was noticed in the liver of rat from diabetic rats treated with $H$. pluvialis extract, the examined sections revealed slight congestion of hepatic sinusoids and activation of Kupffer cells (photomicrograph 7).

Moreover, improved liver sections were noticed in the rat from diabetic rats treated with glibenclamide drug, some examined liver revealed congestion of central vein and hepatic sinusoids as well as activation of Kupffer cells (photomicrograph 8a), whereas, other sections showed no changes except slight activation of Kupffer cells (photomicrograph 8b). 


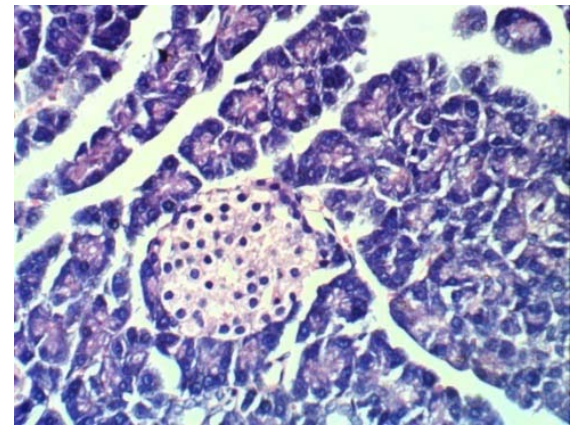

Photomicrograph 1: Pancreas of normal

control rats showing the normal

histological structure of pancreatic acini

and islet's of Langerhan's ( $H$ and $E X$ 400)

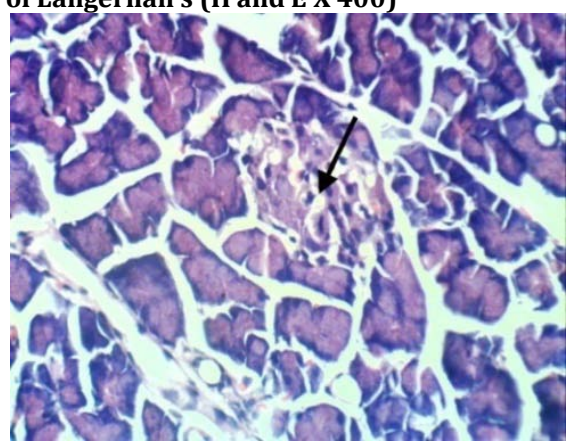

Photomicrograph 3: Pancreas of diabetic ratstreated with $\boldsymbol{H}$. pluvialis extract showing slight vacuolation of cells of islet's of Langerhan's ( $H$ and E X 400)

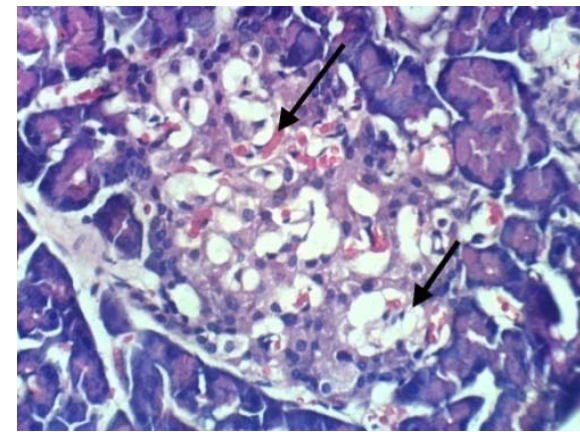

Photomicrograph 2a: Pancreas of diabetic rats showing vacuolations and congestion of islet's of Langerhan's ( $H$ and $E$ X 400)

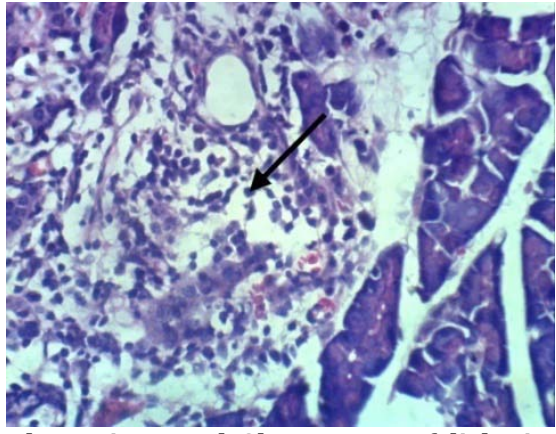

Photomicrograph 2b: Pancreas of diabetic rats showing focal necrosis of pancreatic acini associated with inflammatory cells infiltration ( $\mathrm{H}$ and $\mathrm{E} X \mathrm{400}$ )

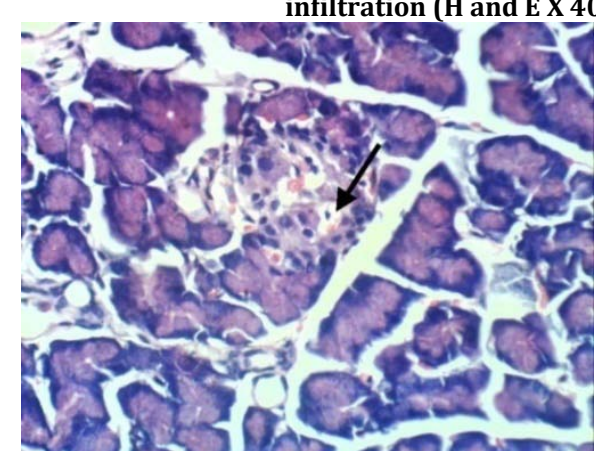

Photomicrograph 4: Pancreas of diabetic rats treated with glibenclamide drug showing slight vacuolation of cells of islet's of Langerhan's (H and E X 400)

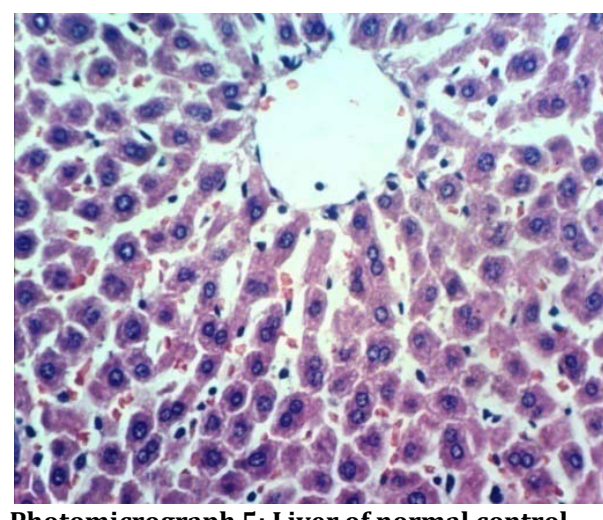

Photomicrograph 5: Liver of normal control

rats showing the normal histological

structure of hepatic lobule ( $H$ and E X 400)

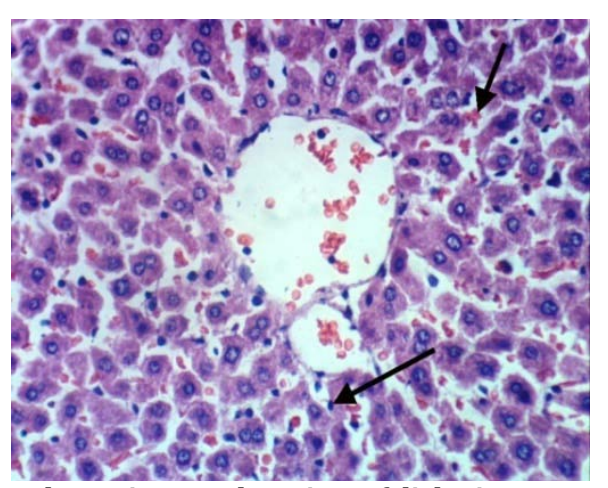

Photomicrograph 7: Liver of diabetic rats treated with $H$. pluvialis extract showing slight congestion of hepatic sinusoids and activation of Kupffer cells (H and E X 400)

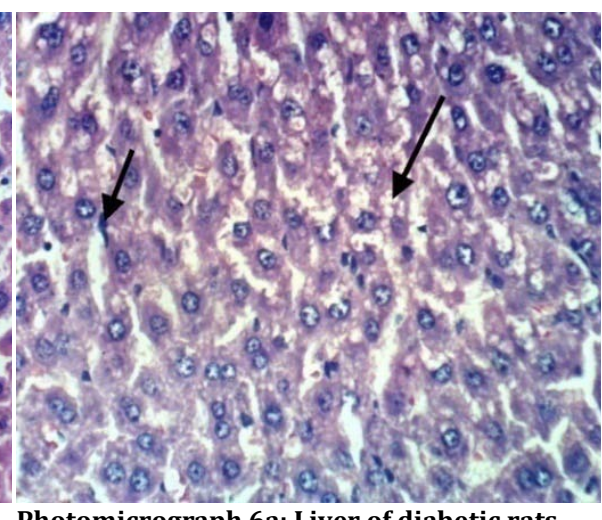

Photomicrograph 6a: Liver of diabetic rats showing Kupffer cells activation and cytoplasmic vacuolization of hepatocytes (H and E X 400)

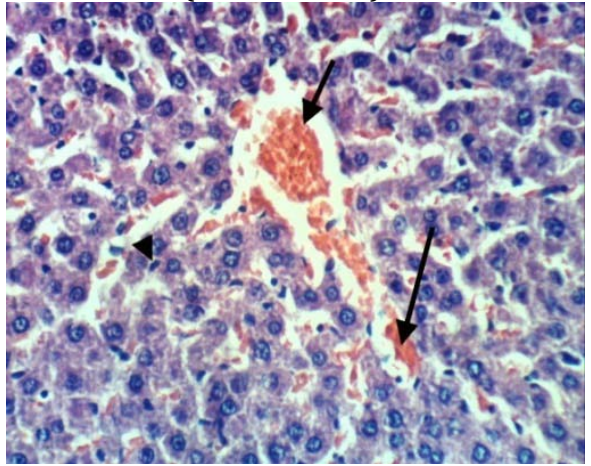

Photomicrograph 8a: Liver of diabetic rats treated with glibenclamide drug showing congestion of central vein and hepatic sinusoids as well as activation of Kupffer cells (H and E X 400)

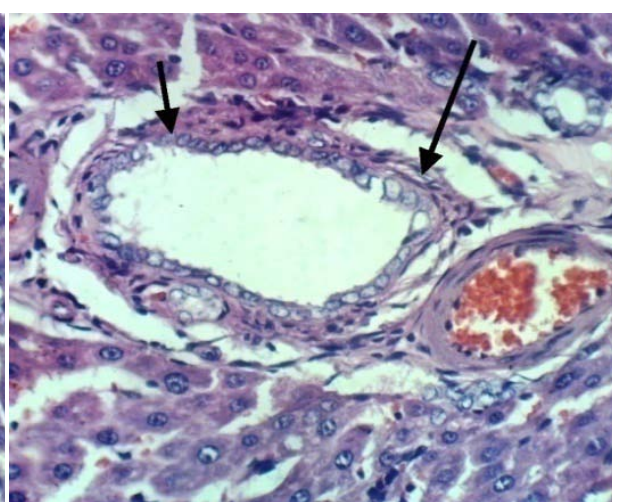

Photomicrograph 6b: Liver of diabetic rats showing cystic dilatation of bile duct and fibroblasts proliferation in the portal triad around the bile duct ( $\mathrm{H}$ and $\mathrm{E} X \mathrm{400}$ )

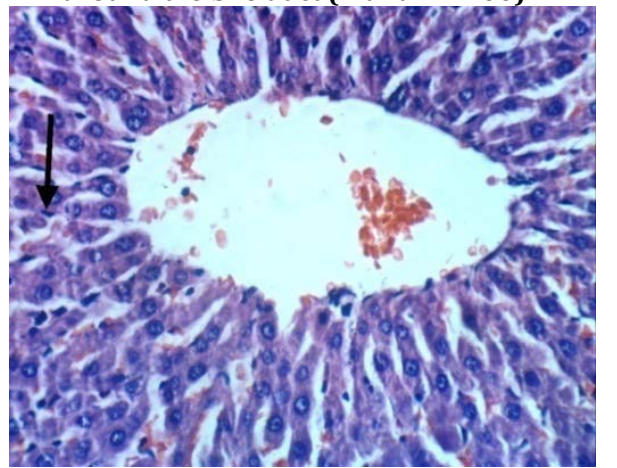

Photomicrograph 8b: Liver of diabetic rats treated with glibenclamide drug showing slight activation of Kupffer cells ( $H$ and E X 400) 
The present histological findings are also agreed with Sheweita et al. [49] who declared that, STZ caused hepatocyte vacuolization and fatty changes, necrosis, dilation of hepatic sinusoids, bile duct and portal vein and cell infiltration in diabetic rats. These observations may be related to the fact that, STZ produced highly reactive intermediates that are detoxified by endogenous glutathione (GSH), however, when these intermediates present in excess amounts, it can deplete GSH stores resulting in allowance the reactive intermediate to damage hepatic and renal cells [51]. ASTA was reported to have a protective effect on the liver of Sprague-Dawley rats against cyclophosphamide-induced oxidative stress [52]. In order that, ASTA is highly accumulated in the liver in addition to, it has powerful antioxidant and anti-inflammatory activities as well as it has a great preventive/therapeutic power to prevent the growth of non-alcoholic steatohepatitis (NASH) [53]. Also, ASTA improved the liver morphology throughout reducing lipid droplets, collagen accumulation and antioxidant status in the liver as evidenced by the elevation in GSH level and antioxidant enzyme activities combined with reduction lipid hydroperoxide level [48].

Supplementation of $H$. pluvialis extract improved the hepatic tissue of diabetic rats, the examined section revealed slight congestion of hepatic sinusoids and activation of Kupffer cells (photomicrograph 7). ASTA is reported to be effective in preventing lipid peroxidation in rat liver microsomes [54]. ASTA could trap radicals at the conjugated polyene chain and the terminal ring moiety throughout molecular interaction such as: the two terminal rings interact with the hydrophilic polar site of membrane phospholipids; and the hydroxyl and carbonyl groups form an intramolecular hydrogenbonded five-membered ring, increasing the hydrophobicity of ASTA [55]. Hence the improved effect of $H$. pluvialis extract on liver tissue may be related to the presence of ASTA that has antioxidant effects.

\section{CONCLUSION}

The presented results markedly indicated that the ethanolic extract of $H$. pluvialis was effective in decreasing the blood glucose level in STZ-induced diabetic rats. The possible mode of action of the algae extract might be through his antioxidant effect of ASTA that may be potentiating the insulin secretion from $\beta$-cells or its insulin-like action. However, the exact mechanism (s) and the nature of the molecule(s) responsible for such effects requires further clinical examination

\section{ACKNOWLEDGMENT}

This work was supported and funded by the project entitled "Biodiesel production from algae as a renewable energy source". Funding organisation: Research Development and Innovation program (RDI), Funding Program: EU-Egypt Innovation Fund, 20142016.

\section{CONFLICT OF INTERESTS}

Conflict of interest declared none

\section{REFERENCES}

1. Lee S, Jeon Y. Anti-diabetic effects of brown algae-derived phlorotannins, marine polyphenols through diverse mechanisms. Fitoterapia 2013;86:129-36.

2. Sharifuddin Y, Chin Y, Lim P, Phang S. Potential bioactive compounds from seaweed for diabetes management. Mar Drugs 2015;13:5447-91.

3. Bishop WM, Zubeck HM. Evaluation of microalgae for use as nutraceuticals and nutritional supplements. J Nutr Food Sci 2012;2:147.

4. Guerin M, Huntley ME, Olaizola M. Haematococcus ASTA: applications for human health and nutrition. Trends Biotechnol 2003;21:210-6.

5. Kishimoto Y, Yoshida H, Kondo K. Potential anti-atherosclerotic properties of ASTA. Mar Drugs 2016;14:1-13.

6. Talero E, García-Mauriño S, Ávila-Román J, Rodríguez-Luna A, Alcaide A, Motilva V. Bioactive compounds isolated from microalgae in chronic inflammation and cancer. Mar Drugs 2015;13:6152-209.
7. Perez-Lopez P, González-García S, Jeffryes C, Agathos SN, McHugh $\mathrm{E}$, Walsh D, et al. Life-cycle assessment of the production of the red antioxidant carotenoid astaxanthin by microalgae: from lab to pilot scale. J Clean Prod 2014;64:332-44.

8. D'Orazio N, Gammone MA, Gemello E, DeGirolamo M, Cusenza S, Riccioni G. Marine bioactives: pharmacological properties and potential applications against inflammatory diseases. Mar Drugs 2012;10:812-33.

9. Stanier RY, Kunisawa MM, Cohn-Bazire G. Purification and properties of unicellular blue green algae (order chroococcales). Bacteriol Rev 1971;35:171-201.

10. Olaizola M. Commercial production of astaxanthin from Haematococcus pluvialis using 25,000-liter outdoor photobioreactors. J Appl Phycol 2000;12:499-506.

11. Liang H, Ma A, Zhang P, Bi SL, Shi DY. Effect of ethanol extract of alga Laurencia supplementation on DNA oxidation and alkylation damage in mice. Asia Pac J Clin Nutr 2007;16:164-8.

12. Milani E, Nikfar S, Khorasani R, Zamani MJ, Abdollahi M. Reduction of diabetes-induced oxidative stress by phosphodiestrase inhibitors in rats. Comp Biochem Physiol Part C: Toxicol Pharmacol 2005;140:251-5.

13. Rajesh V, Perumal P, Sundarrajan T. Antidiabetic activity of methanolic extract of Smilax zeylanica Linn in streptozotocininduced diabetic rats. Internet J Endocrinol 2009;6:1-5.

14. Shalaby NMM, Abd-Alla HI, Aly HF, Albalawy MA, Shaker KH, Bouajila J. Preliminary in-vitro and in vivo evaluation of antidiabetic activity of Ducrosiaanethifolia Boiss. and its linear furanocoumarins. Biomed Res Int 2014;1-13.

15. Dachicourt N, Bailb D, Gangnerou MN, Serradas P, Ravel D, Portha B. Effect of gliclazide treatment on insulin secretion and beta-cell mass in non-insulin dependent goto-kakisaki rats. Eur J Pharmacol 1998;361:243-51.

16. El-Baz FK, Khalil WKB, Booles HF, Aly HF, Ali GH. Dunaliellasalina suppresses oxidative stress, alterations in the expression of pro-apoptosis and inflammation-related genes induced by STZ in diabetic rats. Int J Pharm Sci Rev Res 2016;38:219-26.

17. Trinder P. Determination of blood glucose using 4aminophenazone. J Clin Pathol 1959;22:246-51.

18. Sacks BD. Carbohydrates. In: Burtis CA, Ashwood AR. Eds. tietz Textbook of clinical Chemistry. 2nd ed. Philadelphia WB. Saunders Co; 1994.

19. Reitman S, Frankel S. Glutamic-pyruvate transaminase assay by colorimetric method. Am J Clin Pathol 1957;28:56-8.

20. Allain CC, Poon LS, Chan CS, Richmound W, Fu PC. Enzymatic determination of total serum cholesterol. Clin Chem 1974; 20:470-5.

21. Fassati P, Prencipe L. The determination of triglycerides using enzymatic methods. Clin Chem 1982;28:2077-80.

22. Assmann G, Gotto AM, Cagen JR. HDL cholesterol and protective factors in atherosclerosis. Circulation 2004;109:III8-III14.

23. Stein EA. In: Textbook of Clinical Chemistry. Saunders WB, NW Tietz. ed. Philadelphia; 1986. p. 879-86.

24. Drury RAB, Wallington EA. Preparation and fixation of tissues. In: Drury RAB, Wallington EA. editors. Carleton's Histological Technique. $5^{\text {th }}$ ed. Oxford: Oxford University Press; 1980. p. 41-54.

25. Barde SR, Sakhare RS, Kanthale SB, Chandak PG, Jamkhande PG. Marine bioactive agents: a short review on new marine antidiabetic compounds. Asian Pac J Trop Dis 2015;5:S209-S13.

26. Nizamutdinova IT, Jin YC, Chung JI, Shin SC, Lee SJ, Seo HG, et al. The anti-diabetic effect of anthocyanins in streptozotocininduced diabetic rats through glucose transporter 4 regulation and prevention of insulin resistance and pancreatic apoptosis. Mol Nutr Food Res 2009;53:1419-29.

27. El-Baz FK, Aly HF, Abd-Alla HI, Saad SA. Bioactive flavonoid glycosides and antidiabetic activity of Jatropha curcas on streptozotocin-induced diabetic rats. Int J Pharm Sci Rev Res 2014;29:143-56.

28. Sangeetha Ms, Priyanga S, Hemmalakshmi S, DevakiK. In vivo antidiabetic potential of Cycleapeltata in streptozotocininduced-diabetic rats. Asian J Pharm Clin Res 2015; 1:103-8.

29. Manabe E, Handa O, Naito Y, Mizushima K, Akagiri S, Adachi S, et al. Astaxanthin protects mesangial cells from hyperglycemiainduced oxidative signalling. J Cell Biochem 2008;103:1925-37. 
30. Gandhi GR, Sasikumar P. Antidiabetic effect of Merremiaemarginata Burm. F. in streptozotocin is induced diabetic rats. Asian Pac J Trop Biomed 2012;2:281-6.

31. Abunasef SK, Amin HA, Abdel-Hamid GA. A histological and immune-histochemical study of beta cells in streptozotocin diabetic rats treated with caffeine. Folia Histochem Cytobiol 2014:52:42-50.

32. Cantley J, Ashcroft FM, Ashcroft U. Q and A: insulin secretion and type 2 diabetes: why do $\beta$-cells fail? BMC Biol 2015;13:1-7.

33. Preuss HG, Echard B, Yamashita E, Perricone NV. High dose astaxanthin lowers blood pressure and increases insulin sensitivity in rats: are these effects interdependent? Int J Med Sci 2011;8:126-38.

34. Regnier P, Bastias J, Rodriguez-Ruiz V, Caballero-Casero N, Caballo C, Sicilia D, et al. Astaxanthin from Haematococcus pluvialis prevents oxidative stress on human endothelial cells without toxicity. Mar Drugs 2015;13:2857-74.

35. Sireesha K, Sailaja RP. Oxidative stress and diabetes: an overview. Asian J Pharm Clin Res 2015;8:15-9.

36. Hamden K, Carreau S, Boujbiha MA, Lajmi S, Aloulou D, Kchaou D, et al. Hyperglycaemia, stress oxidant, liver dysfunction and histological changes in diabetic male rat pancreas and liver: protective effect of 17 beta-estradiol. Steroids 2008;73:495-501.

37. Ceron MC, Garcia-Malea MC, Rivas J, Acien FG, Fernandez JM, Río ED, et al. Antioxidant activity of Haematococcus pluvialis cells grown in continuous culture as a function of their carotenoid and fatty acid content. Appl Microbiol Biotechnol 2007;74:1112-9.

38. Tarchalski J, Guzik P, Wysocki H. Correlation between the extent of coronary atherosclerosis and lipid profile. Mol Cell Biochem 2003;246:25-30.

39. Shankarprasad DS, Gundalli S, Mahantesh B, Kashinakunti SV, Sunitha P. Lipid profile in diabetes mellitus. Indian J Pathol Oncol 2015;2:290-4.

40. Chahil TJ, Ginsberg HN. Diabetic dyslipidemia. Endocrinol Metab Clin North Am 2006;35:491-510.

41. Shepherd J. Does statin monotherapy address the multiple lipid abnormalities in type 2 diabetes? Atheroscler Suppl 2005;6:15-9.

42. Vergès B. Pathophysiology of diabetic dyslipidaemia: where are we? Diabetologia 2015;58:886-99.

43. Hussein G, Nakamura M, Zhao Q, Iguchi T, Goto H, Sankawa U, et al. Antihypertensive and neuroprotective effects of astaxanthin in experimental animals. Biol Pharm Bull 2005;28:47-52.

44. Banach M, Serban C, Aronow WS, Rysz J, Dragan S, Lerma EV, et al. Lipid, blood pressure and kidney update 2013. Int Urol Nephrol 2014;46:947-61.
45. McNulty HP, Byun J, Lockwood SF, Jacob RF, Mason RP. Differential effects of carotenoids on lipid peroxidation due to membrane interactions: X-ray diffraction analysis. Biochim Biophys Acta 2007;1768:167-74

46. Jia Y, Kim JY, Jun HJ, Kim SJ, Lee JH, Hoang MH, et al. The natural carotenoid astaxanthin, a PPAR-alpha agonist and PPARgamma antagonist, reduces hepatic lipid accumulation by rewiring the transcriptome in lipid-loaded hepatocytes. Mol Nutrition Food Res 2012;56:878-88.

47. Liu PH, Aoi W, Takami M, Terajima H, Tanimura Y, Natio Y, et al. The astaxanthin-induced improvement in lipid metabolism during exercise is mediated by a PGC-1alpha increase in skeletal muscle. J Clin Biochem Nutrition 2014;54:86-9.

48. Yang Y, Kim B, Lee JY. Astaxanthin structure, metabolism, and health benefits. J Hum Nutr Food Sci 2013;1:1003.

49. Sheweita SA, Mashaly S, Newairy AA, Abdou HM, Eweda SM. Changes in oxidative stress and antioxidant enzyme activities in streptozotocin-induced diabetes mellitus in rats: role of Alhagi maurorum extracts. Oxid Med Cell Longev 2016;1-8. http://dx.doi.org/10.1155/ 2016/5264064

50. Hussein G, Nakagawa T, Goto H, Shimada Y, Matsumoto K, Sankawa U, et al. Astaxanthin ameliorates features of metabolic syndrome in SHR/NDmcr-cp. Life Sci 2007;80:522-9.

51. Rupeshkumar M, Kavitha K, Haldar PK. Role of herbal plants in the diabetes mellitus therapy: an overview. Int J Appl Pharm 2014;6:1-3.

52. Tripathi DN, Jena GB. Astaxanthin intervention ameliorates cyclophosphamide-induced oxidative stress, DNA damage and early hepatocarcinogenesis in rat: role of Nrf2, p53, p38 and phase-II enzymes. Mut Res 2010;696:69-80.

53. Showalter LA, Weinman SA, Qsterlie M, Lockwood SF. Plasma appearance and tissue accumulation of non-esterified, free astaxanthin in C57BL/6 mice after oral dosing of a disodium disuccinate diester of astaxanthin (Heptax). Comp Biochem Physiol Part C: Toxicol Pharmacol 2004;137:227-36.

54. Palozza P, Krinsky NI. Astaxanthin and canthaxanthin are potent antioxidants in a membrane model. Arch Biochem Biophys 1992;297:291-5.

55. Goto S, Kogure K, Abe K, Kimata Y, Kitahama K, Yamashita E, et al. Efficient radical trapping at the surface and inside the phospholipid membrane is responsible for the highly potent antiperoxidative activity of the carotenoid astaxanthin. Biochim Biophys Acta 2001;1512:251-8.

\section{How to cite this article}

- Farouk K EL-Baz, Hanan F Aly, Sayeda M Abdo, Safaa A Saad The healing potency of Haematococcus pluvialis extract for treating type 2 diabetes in rats. Int J Pharm Pharm Sci 2017;9(1):192-198 